九州大学学術情報リポジトリ

Kyushu University Institutional Repository

\title{
Numerical and Experimental Study of Flow Behaviours in Porous Structure of Aluminium Metal Foam
}

Sat ishwara Rao Narasimmanaidu

Fakulti Kejuruteraan Mekanikal, Universiti Teknikal Malaysia Melaka

Fadhi lah Shikh Anuar

Fakulti Teknologi Kejuruteraan Mekanikal dan Pembuatan, Universiti Teknikal Malaysia Melaka

Fat imah Al-Zahrah Mohd Sa' at

Fakulti Kejuruteraan Mekanikal, Universiti Teknikal Malaysia Melaka

Ernie Mat Tokit

Fakulti Kejuruteraan Mekanikal, Universiti Teknikal Malaysia Melaka

https://doi.org/10.5109/4491842

出版情報：Evergreen. 8 (3)，pp.658-666，2021-09. 九州大学グリーンテクノロジー研究教育センター バージョン：

権利関係 : 


\title{
Numerical and Experimental Study of Flow Behaviours in Porous Structure of Aluminium Metal Foam
}

\author{
Satishwara Rao Narasimmanaidu1, Fadhilah Shikh Anuar ${ }^{2,3 *}$, Fatimah Al-Zahrah \\ Mohd Sa'at ${ }^{1,3}$ Ernie Mat Tokit ${ }^{1,3}$ \\ ${ }^{1}$ Fakulti Kejuruteraan Mekanikal, Universiti Teknikal Malaysia Melaka, Hang Tuah Jaya, \\ Durian Tunggal, 76100 Melaka, Malaysia \\ ${ }^{2}$ Fakulti Teknologi Kejuruteraan Mekanikal dan Pembuatan, Universiti Teknikal Malaysia Melaka, \\ Hang Tuah Jaya, Durian Tunggal, 76100 Melaka, Malaysia \\ ${ }^{3}$ Centre for Advanced Research on Energy, Universiti Teknikal Malaysia Melaka, \\ Hang Tuah Jaya, Durian Tunggal, 76100 Melaka, Malaysia
}

*E-mail: fadhilah@utem.edu.my

(Received January 7, 2021; Revised September 6, 2021; accepted September 6, 2021).

\begin{abstract}
This study conducted a simulation and an experimental study on a channel that was partly filled with open-cell metal foam block. Different blockage ratios have been considered, where the foam height could occupy more than half of the channel size. The aim is to investigate the flow behaviours across the complicated structure of the porous medium. Results show that the use of Ergun and Forchheimer models showed a similar stagnant region and recirculation zone in the partially filled channel, which agreed with the experimental results. However, the deviation in pressure drop performance at a high blockage ratio is noticeable.
\end{abstract}

Keywords: metal foam; flow behaviours; infrared thermography; CFD; pressure drop

\section{Introduction}

The open-cell metal foam is a kind of porous media, and a promising material as a heat exchanger in a wide range of industries. Many studies have proved the superior thermal capabilities of the metal foam, but its large pressure drop effects is one of the main concerns in its implementation. Thus, a partially filled heat exchanger design can be proposed to reduce the pressure drop as long as its augmented heat transfer performance is maintained. Since the last decade, the metal foam studies have adapted the classical model of porous media (e.g., Darcy's Law ${ }^{1)}$ ), and its improved version, the development of Darcy to turbulence can be found in past work by Lage ${ }^{2}$. Even though the studies on fully filled metal foam heat exchanger designs are matured enough, there are limited studies on the partially filled designs, especially through the experimental work $^{3}$. It is understandable that experimental study is tedious work and difficult ${ }^{4}$, while the computational fluid dynamics (CFD) method is more common and a faster approach to study fluid dynamics, for example, to predict flow near a surface ${ }^{5)}$ and in a large space ${ }^{6}$. However, there should be a sound basis of the underlying theory that has been validated by experimental data, particularly for the open-cell metal foam, considering its complex porous structure and geometrical arrangement. Since the experimental studies are really limited, it could be the reason for the missing information on the secondary flows and unsaturated (no flow) regions in the partially filled design ${ }^{7}$. It is a common approach to adapt Darcy's Law into open-cell metal foam studies, assuming average flow rate and saturated flows in its porous structure. However, in the case of a partially filled setup with high enough open-cell metal foam, the saturated flow assumption is not necessarily true, as the randomness and interconnected pores can be a significant barrier, forcing the fluid to leave the porous region ${ }^{7)}$. As a result, some of the pore spaces are no longer filled with fluid. In another experimental study ${ }^{8}$, it was found that a thermal entry length must also be taken into account as the classical porous media model could not accurately describe the thermal development in the metal foam. The study suggested for a new theory and analytical treatment to compensate the missing parameter in the existing model

Wang et al. ${ }^{9)}$ conducted an analytical work on a partially filled configuration and found that the flow characteristics at relatively high speed are different compared to those under low velocity. They suggested an optimization on the porous filling since the effects of pressure drop are greatly influenced by the complex microstructure of metal foam. Mehmet et al. ${ }^{10)}$ studied Forchheimer forced convection and pressure drop in a rectangular channel that are partly 
filled with 10 PPI and 20 PPI aluminium foam with four different designs: (1) completely full, (2) convex, (3) concave and (4) triangular against the flow. The study shows that when the surface curvature parameter (defined surface curvature), $\mathrm{k}=0$, the pressure gradient increased 8 times from the minimum Darcy velocity of $0.25 \mathrm{~m} / \mathrm{s}$. For $\mathrm{k}=0.5$, the pressure gradient increased 3.5 times from maximum Darcy velocity of $15.5 \mathrm{~m} / \mathrm{s}$. It was concluded that a lower pore density foam like 10 PPI caused only a low-pressure drop effect. However, particle laden fluids may affect flow efficiency ${ }^{11)}$, and a fluctuation of pressure drop occurred even with the low pore density foam under this condition ${ }^{12)}$. Since flow regimes also play an important role in influencing the pressure drop performance $^{13)}$, the exact model for the partially filled configuration is quite difficult to be formulated.

Kotresha and Gnanasekaran ${ }^{14)}$ modelled various foam heights, from partially filled to fully filled channels in their simulation using ANSYS FLUENT. They used Darcy extended Forchheimer model to describe the metal foam in their numerical model and considered it as an isotropic homogenous medium, which is similar to many other studies ${ }^{15,16}$. At the interface between the metal foam and the fluid layer (or clear region), continuity in shear stress was applied, and by comparing aluminium and copper metal foams with pore densities of 20 PPI and 40 PPI, they found that the pressure drop increases with foam height and inlet fluid velocity, as expected. The velocity in the clear region also increases as the foam height increases. Meanwhile, Alvandifar et al. ${ }^{17)}$ found that by increasing the metal foam thickness, the heat transfer rate remains almost constant while the pressure drop increases. The study stated that metal foam wrapped tube banks that are only partially covered with foam would reduce the pressure drop by $60 \%$.

The solid-liquid interface in a partially filled design is still debated by many researchers ${ }^{18)}$. An analytical study on a channel partly filled porous medium has assumed jump condition at interface between the porous structure and clear region ${ }^{19}$. However, experimental studies on a channel that partially filled with a complicated porous structure like the open-cell metal foam found the existence of a slip condition based on the flow patterns found at the interface region $^{15,16)}$. The studies also found that the use of continuous shear stress at the interface would not give a sharp gradient velocity profile as found in the past study ${ }^{19)}$. Meanwhile, another study ${ }^{20}$ ) derived a generalized interface model and claimed its suitability to diverse groups of porous media. Unfortunately, the relevancy of their mathematical model with a real metal foam has not yet been proven. Due to the randomness and interconnected ligaments of the metal foam, the complicated flow behaviours must be explained in a different light if necessary. The investigation of flow pattern have been done in small systems like microchannels ${ }^{21)}$. Thus, understanding the overall flow patterns, e.g., velocity contours and streamlines would be helpful before jumping straight into modelling the interface region, exclusively for the open-cell metal foam. Perhaps, there is only a small difference in the pressure drop from a simulation that utilizes the existing classical porous media model and the experiment results.

However, there is almost no published literature that compared the results of their numerical studies with experimental data, as shown by Sauret ${ }^{15,16)}$. Many numerical studies assumed the classical model of porous media would be able to describe the flow behaviours in the partially filled configuration as accurately as the fully filled configuration. However, experimental results with real foam samples show the possibility of stagnant regions in the porous structure and the existence of secondary flows $^{7}$. Thus, the assumption of uniform pore velocity, no-slip or jump condition at the foam interface could be inaccurate to explain the exact flow behaviours in the channel. Instead of proposing a new model for the interface region, this study used an existing classical model in the literature: Ergun ${ }^{22}$ and Forchheimer') equations to describe the effects of a real metal foam in numerical simulations. The flow behaviours and pressure drop performances of 10 PPI and 30 PPI and different blockage ratios (a ratio of heights between the metal foam and rectangular channel) were investigated. In addition, flow visualization using the infrared thermography (IRT) technique was also conducted. The results are compared to past experimental data ${ }^{7)}$.

\section{Simulation and Experimental Setup}

\subsection{Computational Domain and Boundary Condition}

This study used ANSYS-FLUENT v15.2 software to conduct simulations on flow behaviours across a partially filled channel with 10 PPI and 30 PPI metal foam and investigate the pressure drop performances. A twodimensional computational domain was considered based on the symmetry design of a rectangular channel ${ }^{7)}$ as shown in Fig. 1. The domain consists of a section partially filled with porous medium, upstream region and downstream region, with the domain height of $0.08 \mathrm{~m}(\mathrm{H})$. In this study, two blockage ratios are considered: (1) h/H $=0.13$ and $(2) \mathrm{h} / \mathrm{H}=0.39$, where $\mathrm{h}$ is the porous medium height and $\mathrm{H}$ is the channel height.

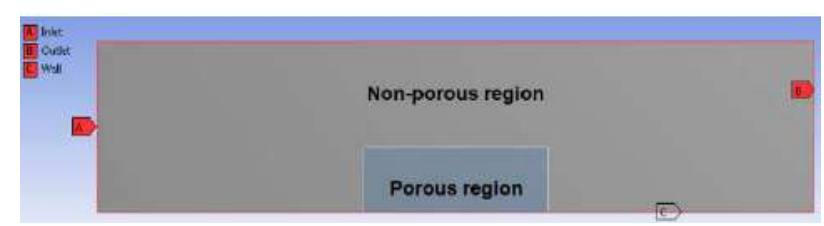

Fig. 1: Boundary condition in CFD simulation

The inlet of the computational domain was defined with a uniform velocity boundary condition of $6.2 \mathrm{~m} / \mathrm{s}$ and the outlet was defined with zero pressure. Based on the inlet velocity $\mathrm{u}_{0}$, the Reynolds number, $R e$ for the flow inside the domain is about 22,000. To capture the turbulent 
characteristics of the flow, the k- $\varepsilon$ model is used for the non-porous (clear) region of the domain. This model has been used to simulate flow over terrain and other applications ${ }^{23}$. The convergence was set at $10^{-6}$ for energy equation, while the continuity, $\mathrm{k}-\varepsilon$ was set at $10^{-3}$. This study used the continuity in shear stress at the interface condition, and Navier-Stokes equation for the clear (nonporous) region. The metal foam in the experiment ${ }^{7)}$ is considered as a porous medium (porous zone) in the present study, where the Ergun-Forchheimer equation is used to describe the inertial and viscous effects of the metal foam in the simulation analysis. The Forchheimer's equation in Eq. (1) ${ }^{24)}$ is an extension of Darcy's equation for turbulent flow through a porous medium, where $1 / \alpha$ is the viscous resistance coefficient $\left(1 / \mathrm{m}^{2}\right)$ and $\beta$ is the inertial resistance coefficient $(1 / \mathrm{m})$. These two parameters are used as the inputs in the simulation. Meanwhile, Ergun's equation in Eq. (2) are commonly used to determine the pressure drops of fluid flow through packed beds, made of cylinders, rough sands, or other sphereshaped particles. Besides that, it has also been typically used in investigating pressure drop characteristics and velocity in open-cell metal foams.

$$
\begin{gathered}
-\nabla p^{*}=\frac{\mu}{\alpha} u^{*}+\beta \rho u^{* 2} \\
-\nabla p^{*}=\frac{150 \mu(1-\varepsilon)^{2} u^{*}}{d_{p}^{2} \varepsilon^{3}} u^{*}+1.75 \frac{(1-\varepsilon)}{\varepsilon^{3}} \frac{\rho u^{* 2}}{d_{p}}
\end{gathered}
$$

where, $\nabla p^{*}$ is pressure gradient of flow direction $(\mathrm{Pa} / \mathrm{m})$, $\mathrm{u}^{*}$ is flux per unit area of the porous medium, and $\rho$ is the density of the fluid. When combining Eq. (1) and (2), the correlations of $1 / \alpha$, viscous coefficient resistance and $\beta$, inertial resistance coefficient can be obtained as shown in Eq. (3) and Eq. (4) ${ }^{22}$, respectively.

$$
\begin{aligned}
& \alpha=\frac{d_{p}^{2}}{150} \cdot \frac{\varepsilon^{3}}{(1-\varepsilon)^{2}} \\
& \beta=\frac{3.5}{d_{p}} \cdot \frac{(1-\varepsilon)}{\varepsilon^{3}}
\end{aligned}
$$

Table 1. The parameters and boundary conditions for a rectangular channel and porous medium

\begin{tabular}{|l|l|l|}
\hline \multicolumn{3}{|c|}{ Open-cell metal foam ${ }^{7}$} \\
\hline Pore density (PPI) & 10 & 30 \\
\hline Porosity (-) & $0.82-0.91$ & $0.88-0.94$ \\
\hline Pore diameter, $\boldsymbol{d}_{\boldsymbol{p}}$ (m) & 0.0026 & 0.00087 \\
\hline Porous medium & \\
\hline Viscous resistance coefficient* & $7.403 \times 10^{4}$ & $1.917 \times 10^{5}$ \\
\hline Inertial resistance coefficient* & 265.75 & 480.47 \\
\hline Length, L (m) & 0.09 \\
\hline Height, h (m) & $0.01,0.03$ \\
\hline Material & Aluminium \\
\hline \multicolumn{2}{|c|}{ Operating condition and channel dimension } \\
\hline Medium & Air \\
\hline Flow velocity, u (m/s) & 6.2 \\
\hline Channel width, W (m) & 0.100 \\
\hline
\end{tabular}

\begin{tabular}{|l|l|}
\hline Channel height, $\mathbf{H}$ (m) & 0.078 \\
\hline Channel length, $\mathbf{L}(\mathbf{m})$ & 0.350 \\
\hline *Calculated using Eq. (1) to (4).
\end{tabular}

*Calculated using Eq. (1) to (4).

The viscous and inertial resistance coefficients are required to define the properties of porous zone and the parameters in the equations are based on the porosity and the pore size of a real metal foam as listed in Table 1. The range of values for the porosity is for different foam heights used in this study. The lowest porosity value represents the thinnest foam, and the highest porosity value represents the thickest foam. In the CFD simulation, the SIMPLE algorithm method is chosen to enforce mass conservation and obtain pressure field.

\subsection{Numerical method validation}

This study compared the simulation results with the experimental data of the same setup ${ }^{7}$ but considering a solid block with blockage ratio of 0.39 to partially fill the channel. Thus, the non-porous or interface model is required in this first step of validation. The result shown in Fig. 2 shows that the present simulation provides the same results as the experimental data where recirculation zones exist at the upstream and downstream regions with a vena contracta appearing near the leading edge, on the top of the porous medium, which is marked as ' $x$ '. It shows that the simulation and parameter settings used in this study are acceptable for further analysis with the porous medium.

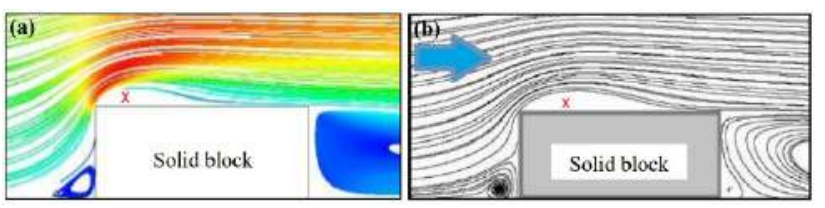

Fig. 2: Comparison between present simulation and experimental $\operatorname{data}^{7}$ ) on a partially filled channel

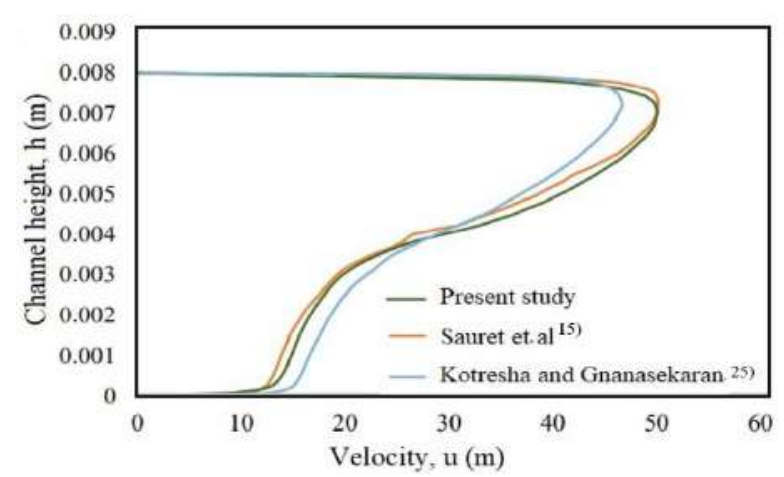

Fig. 3: Comparison of velocity profiles between present simulation and other simulations ${ }^{15,25)}$ on a partially filled channel

A porous zone is introduced as the replacement of the solid block to represent the open-cell metal foam in the partially filled channel and a "touch-up" on the interface region is done using the mesh refinement method. The mesh was tested for grid independency and it was found that the model with total grid number of 4020 is sufficient 
to provide results that are independence of the grid size. A comparison between our present result with the other numerical work ${ }^{15,25)}$ is shown in Fig. 3 in terms of velocity profiles. The studies introduced the metal foam as isotropic homogenous porous medium and as the source term to the momentum equation using the Darcy Extended Forchheimer model. Both studies also refined the interface regions and used the $\mathrm{k}-\varepsilon$ model to define the nonporous region. The present simulation using the ErgunForchheimer Equation shows an acceptable agreement with their models.

From the simulation results, velocity contours were extracted, focusing on the flow behaviours inside the porous structure, qualitatively. Meanwhile, the pressure data was collected at two locations: $125 \mathrm{~mm}$ from the middle of the porous block (or V1) towards the right, P2 and left, P1 of the domain as shown in Fig. 4. This data can be used to determine the pressure drop effects due to different blockage ratios and pore densities.

\begin{tabular}{|l|l|l|}
\hline \multicolumn{1}{|c|}{ P1 } & V1 & P2 \\
\cline { 2 - 3 } & $\begin{array}{l}\text { Porous } \\
\text { region }\end{array}$ \\
\hline
\end{tabular}

Fig. 4: Location of pressure data obtained from the simulation

\subsection{Experimental setup for infrared thermography}

To understand the flow behaviours across a real opencell metal foam, an experiment using infrared camera was also conducted. This infrared thermographic (IRT) technique that is fast and non-invasive is a good approach to investigate boundary layers on wind turbines ${ }^{26)}$, flow instability ${ }^{27)}$, and flow in an open-cell metal foam ${ }^{7}$ without disturbing the flow inside the system. In this study, the experiments were conducted using metal foams with pore densities of $10 \mathrm{PPI}, 30 \mathrm{PPI}$ and $40 \mathrm{PPI}$. The pore diameter and porosity of 10 and 30 PPI foams can be found in Table 1, while the pore diameter and porosity of the $40 \mathrm{PPI}$ are $0.000635 \mathrm{~m}$ and $0.926^{28)}$, respectively.
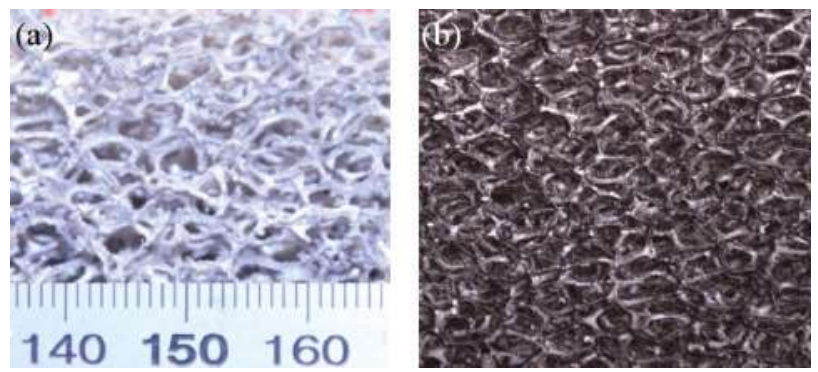

Fig. 5: (a) Aluminium foam and (b) painted black foam

The blockage ratios used in the experiment are also the same as our parameter settings in the simulation as listed in Table 1. Fig. 5 shows the original aluminium metal foam sample, and its appearance must be painted with an opaque colour, in this case, black to match the IRT method. By coating the metal foam with a very thin layer of opaque material, its surface radiation properties can be improved to provide higher emissivity. An infrared camera (FLIR T650sc) was used to sense the infrared energy from the foam surface, calculate the temperature values and present the temperature fields. To ensure the flow behaviours across the metal foam in the channel can be seen through this technique, a high emissivity window (Quartz, $\varepsilon=0.93)$ was also used as the channel wall.

This experiment was conducted in a rectangular channel with the details of its size listed in Table 1. Using a side channel blower (1.1 kW, ELMO-G), the surrounding air is drawn into the rectangular channel but passing through an electric heater ( $3 \mathrm{~kW}$ ) first, located at the upstream of the test section. The test section with a quartz window is focused as the camera's field of view. To create a steady state condition, the airflow at a speed of $6.2 \mathrm{~m} / \mathrm{s}$ is heated to $60^{\circ} \mathrm{C}$, and left running for at least 30 minutes. The temperature data from the surface thermocouple on the window, must be constant before capturing the images of the block inside the channel. To visualize the hot flow (air) inside the porous structure, a cooling circulator unit (Julabo GmbH; Model F25 MV) was turned on to maintain the temperature of a mixture of water/ethylene glycol (50:50 composition) at $20^{\circ} \mathrm{C}$. The mixture coolant moved underneath (separated wall) of test section and recirculated back into the circulator unit.

Table 2. Specifications of infrared camera

\begin{tabular}{|l|l|}
\hline Model & T650sc (FLIR) \\
\hline Spectral range ( $\mu \mathrm{m})$ & $7.5-13$ \\
\hline Focal length $(\mathbf{m m})$ & 25 \\
\hline Resolution (pixel) & $640 \times 480$ \\
\hline Camera f/\# & $\begin{array}{l}\mathrm{f} / 1.0, \text { Integrated Lens } 18 \mathrm{~mm} \\
\left(25^{\circ}\right)\end{array}$ \\
\hline Detector type & Uncooled Microbolometer \\
\hline Detector pitch $(\boldsymbol{\mu m})$ & 17 \\
\hline
\end{tabular}

Table 3. Uncertainty in experimental measurements

\begin{tabular}{|l|l|l|}
\hline Parameters & Measurement device & Uncertainty \\
\hline $\begin{array}{l}\text { Flow rate } \\
\text { (air) }\end{array}$ & $\begin{array}{l}\text { Calibrated gauge } \\
\text { valve }\end{array}$ & $\pm 5 \%$ \\
\hline $\begin{array}{l}\text { Flow rate } \\
\text { (coolant mixture) }\end{array}$ & $\begin{array}{l}\text { Digital flow sensor } \\
\text { (Model: IFM Efector; } \\
\text { SM 6000) }\end{array}$ & $\pm 2 \%$ \\
\hline Wall temperature & $\begin{array}{l}\text { Infrared camera } \\
\text { (Model: Flir, T650sc) }\end{array}$ & $\begin{array}{l} \pm 1 \circ \mathrm{C} \text { of the } \\
\text { temperature } \\
\text { data }\end{array}$ \\
\hline
\end{tabular}

The details of the experimental setup can be found in our past literature ${ }^{7,29)}$. Instead of a PIV camera, a thermal camera was installed at the same location, in front of the clear window of the rectangular channel. Note that the camera captured the temperature distribution and visualized the flow behaviours across the porous microstructure through the radiation effects of the quartz 
window, converting it to an electronic signal, so that the results of $2 \mathrm{D}$ temperature field can be obtained. The images are analysed using FLIR Tools software. Table 2 shows the specifications of the infrared camera used in the experiment and Table 3 shows the uncertainty in the measurements ${ }^{7)}$.

\section{Results and discussion}

The velocity distributions through the partially filled section, including the porous structure and the upstream and downstream sections are shown as velocity contours

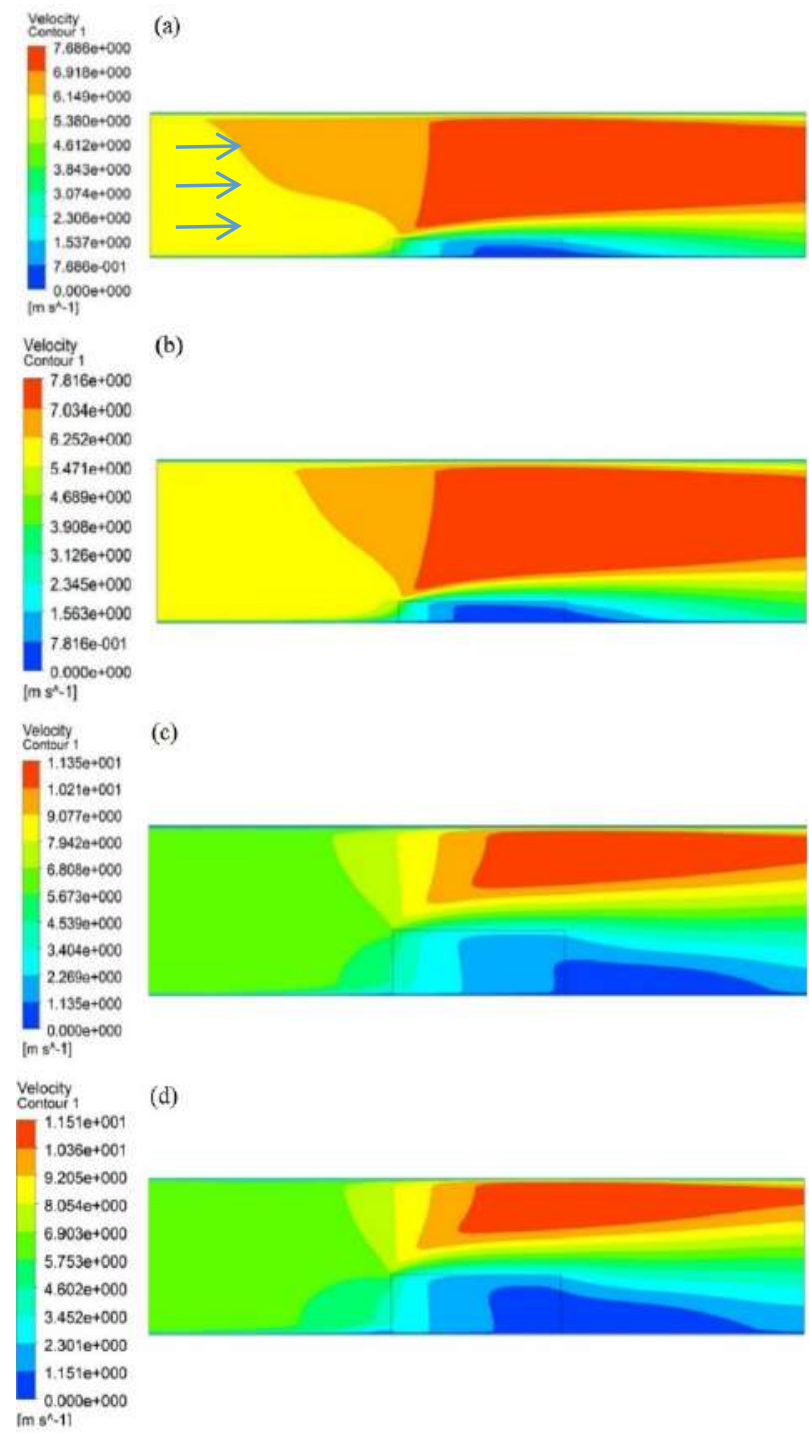

in Fig. 6, where the lowest velocity appears in the porous medium as expected, typically known as pore velocity, $\mathrm{u}_{\mathrm{p}}$.

Fig. 6: Velocity contours at $6.2 \mathrm{~m} / \mathrm{s}$ (a) h/H = 0.13, $10 \mathrm{PPI}$, (b) $\mathrm{h} / \mathrm{H}=0.13,30 \mathrm{PPI}$, (c) $\mathrm{h} / \mathrm{H}=0.39,10 \mathrm{PPI}$ and (d) $\mathrm{h} / \mathrm{H}=$ 0.39, 30 PPI

The velocity contours inside the porous block shows a variation of pore velocity, regardless of the pore density and blockage ratio. A part of the incoming flow from the upstream regions enters the leading edge of the porous block and the velocity is reduced drastically, from $6.2 \mathrm{~m} / \mathrm{s}$ to $0 \mathrm{~m} / \mathrm{s}$ as flowing through the ligament constructions. It also shows a presence of stagnant region in the porous structure (no flow region) starting from the half-length of the porous block towards the rear end. For the lowest blockage ratio in this study, $\mathrm{h} / \mathrm{H}=0.13$, there is no significant difference in the velocity contour in the porous block of 10 PPI and 30 PPI. The clear region on the top of the porous medium, $\mathrm{h} / \mathrm{H}=0.13$ shows only a slightly higher velocity compared to the inlet velocity, which is up to $7.8 \mathrm{~m} / \mathrm{s}$ as expected. The smaller cross-sectional area of the clear (free stream) region in the partial section as compared to the original size of channel cross-section increases the flow velocities in the clear region. In the case with the highest flow restriction (Fig. 6 (d)), the velocity contour at the entrance region is in green colour $(\mathrm{u}=6.91$ $\mathrm{m} / \mathrm{s}$ ), which covered almost half of the upstream region. There is a colour transition from light green $(\mathrm{u}=8.05 \mathrm{~m} / \mathrm{s})$ to light blue $(\mathrm{u}=2.31 \mathrm{~m} / \mathrm{s})$ at the leading edge of the porous medium implying the reduction in the velocity before the flow enters the porous medium. Meanwhile, the effects of pore density on the pore velocity can be clearly seen in the blockage ratio of 0.39 . For the $30 \mathrm{PPI}$, there is a larger no-flow region compared to the $10 \mathrm{PPI}$, which occurs right after the middle part of the porous block. Meanwhile, the 10 PPI shows the presence of very low velocity and stagnant region at the rear edge, suggesting that the recirculation zone that appears behind the block is also covering a part of the porous structure. Meanwhile, instead of the possibility of a circulation zone inside the porous structure of $30 \mathrm{PPI}$, the idea of a no-flow region in its structure is more prominent due to higher ligament restrictions and smaller pore sizes. For all cases (Fig. 6 (a) to (d)), there are boundary layers on the top of the porous medium, suggesting a no-slip condition at the interface of the porous medium.

However, to obtain a better understanding on the flow behaviours inside the porous structure and interface, the results of the present study are also compared to the previous experimental data $^{7)}$ of the same setup. The flow streamlines are shown in Fig. 7. The experimental study ${ }^{7)}$ found a secondary flow, or outcoming flow through the top interface of the porous foam, which is shown in Fig. 7 (f) and (h). The results of the present study agree with their findings, showing similar flow behaviours. However, the size and location of the recirculation zones are quite different, where larger recirculation zones appear in the experimental results as compared to the numerical simulation. However, it is important to note that the experimental study ${ }^{7}$ ) used Particle Image Velocimetry (PIV) and their analyses are based on the availability of the seeding particles near the porous block, and applied cross-correlation method on each adjacent interrogation area. The porous structure was mapped out from their analyses. Meanwhile, this numerical study acknowledged the presence of porous blocks in the partially filled channels. Thus, the findings in the numerical results are probably more accurate in terms of the location of recirculation zones, supporting the nature of the block itself - the porous material. Meanwhile, the wake behind 
the block is characterized by a region of significant velocity reduction and large vortices ${ }^{30}$.

At the interface region, both numerical and experimental results show the outgoing flow from the porous structure. However, flow trajectories seem stronger in the experimental results in Fig. 7 (f) and (h), as compared to the numerical results. This difference could be attributed to our assumption in the numerical analyses. It used a refined mesh at the interface and the ErgunForchheimer equation to describe the flow inside the porous structure. Nevertheless, the present study found that the use of Ergun-Forchheimer could be more accurate to explain the flow behaviours in the porous structure of metal foam as compared to the previous numerical studies $^{16)}$ as our streamline results are similar to the experimental data. Both experimental and present numerical results agree that there is no recirculation zone behind the $10 \mathrm{PPI}$ foam, $\mathrm{h} / \mathrm{H}=0.39$, while a recirculation zone exists in the rest of the cases. The differences between these two approaches are only in the size of recirculation zone and the onset of the flow separation, for the more restricted porous structure, e.g., 30 PPI foam. The reliability of CFD simulation and the ErgunForchheimer equation to represent the flow behaviours in more porous structures like 10 PPI foam is evident. The simulation shows that the flow inside the 30 PPI foam (Fig. 7 (d)) has been restricted earlier than the 10 PPI foam (Fig. 7 (e)), forcing a higher degree of vertical flow in the porous structure with $\mathrm{h} / \mathrm{H}=0.39$. This higher blockage ratio with lesser flow passages provides larger flow resistance to the incoming flow, resulting in a larger recirculation zone at the downstream region.
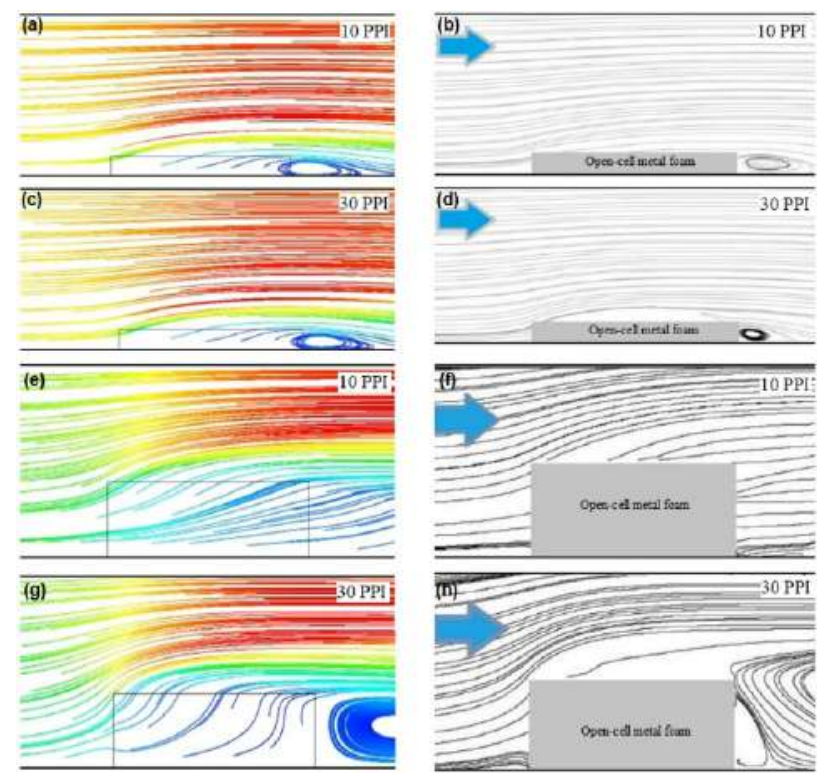

Fig. 7: Comparison of numerical and experimental ${ }^{7)}$ streamlines: (a) - (d) h/H = 0.13, (e) - (f) h/H = 0.39

To gain more insight of flow behaviours in higher restricted flow regions in the porous structure, this study included a higher pore density foam; 40 PPI when capturing the infrared images of the metal foams. The

infrared images for different pore densities and blockage ratios are shown in Fig. 8, where only the porous structure without the clear or non-porous regions are presented. The red and blue arrows indicate the locations of maximum and minimum temperatures, respectively. Generally, it shows some parts of the porous block with $\mathrm{h} / \mathrm{H}=0.39$ (Fig 8 (a) and (b)) are in the lower temperature region (blue colour), representing the stagnant or low velocity regions. The maximum temperature regions are found to be from the leading edge towards one-third of the porous structure, covering more areas near to the interface region. It proved that a part of the hot fluid leaves the porous structure through the interface region going through massive poreligaments, which is similar to the simulation results shown in Fig. 7 (e) and (g).

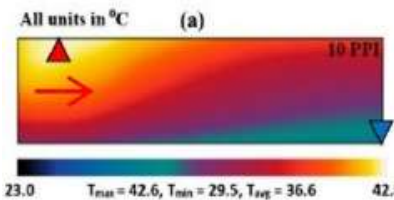

(b)

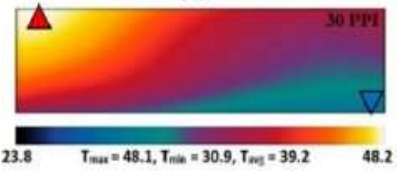

(c)

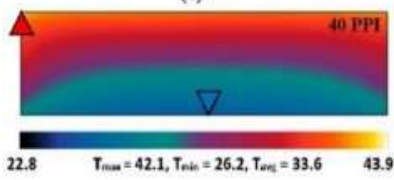

(d)

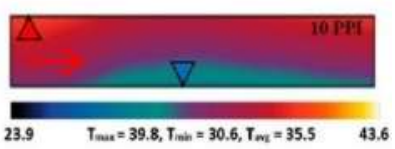

(e)

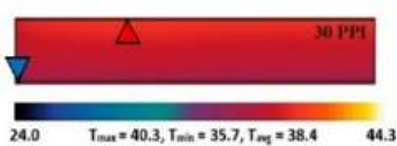

(f)

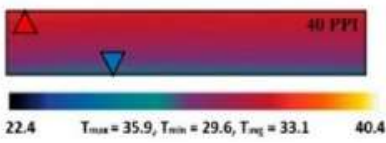

Fig. 8: Thermograms for different pore density and blockage ratio: (a) - (c) h/H =0.39, and (d) - (f) h/H = 0.13

The difference in temperature distributions across the quartz wall, which represent the effects of radiation from the porous structure distinguishes the effects of blockage ratios and pore densities on the flow pattern. It is noteworthy to mention that without the hot flow, if the air is at room temperature and at the same time the coolant mixture is recirculated at $20^{\circ} \mathrm{C}$ at the bottom side of the test section, the same temperature distribution results would not be produced as shown in Fig. 8. Those areas are the hot fluid pathways emitting higher radiation; thus, distinguishing itself from the unfavourable paths. Interestingly, the highest ligament construction, the 40 PPI metal foam shows a different flow pattern (see Fig. 8 (c)).

Specifically, two different temperature fields can be clearly seen in higher blockage ratio, $\mathrm{h} / \mathrm{H}=0.39$. This could be attributed to very small pore size, and the $40 \mathrm{PPI}$ may resemble a solid (aluminium) block, where the hot fluid passes through the clear region instead of the porous region. The higher temperature distributions in the upper part of the porous structure could be the heat transferred from the hot fluid. Meanwhile, the temperature of the lower part of the porous structure is reduced due to the cold water-ethylene glycol mixture. For $\mathrm{h} / \mathrm{H}=0.13$, more 
porous structures like 10 PPI allows both the hot fluid and cold mixture from the bottom side to influence its structure temperature. While the higher PPIs tend to exhibit higher temperature distributions. It shows that smaller pore sizes with a closer ligament construction caused the increase of the porous structure temperature.

Fig. 9 shows the results of simulation, where the streamlines across the denser foam; 40 PPI foam has different flow directions and recirculation zone size as compared to the results found in more porous structures like 10 and 30 PPI foams in Fig. 7 (e) and (g), respectively. The pore velocities are mostly $0 \mathrm{~m} / \mathrm{s}$, which represent a no-flow or a stagnant area in the porous region, with a low velocity value of less than $3.0 \mathrm{~m} / \mathrm{s}$ near the frontal area of the foam block. Even with the use of the same blockage ratio, the presence of the recirculation zone at the back of $40 \mathrm{PPI}$ is so much smaller than $30 \mathrm{PPI}$, and the onset of its formation does not start from the interface region. Since there is no upward flow direction in the porous region towards the interface, the result shows that the outgoing flow through the interface region is insignificant for 40 PPI. Thus, two distinct areas can be seen from this streamline based on the velocity value range and the flow directions, confirming the separation of free stream (nonporous) region and the porous region in the high-density foam. This result supports the experimental findings (thermogram), where two different temperature fields can be found in those regions, as shown in Fig. 8 (c).

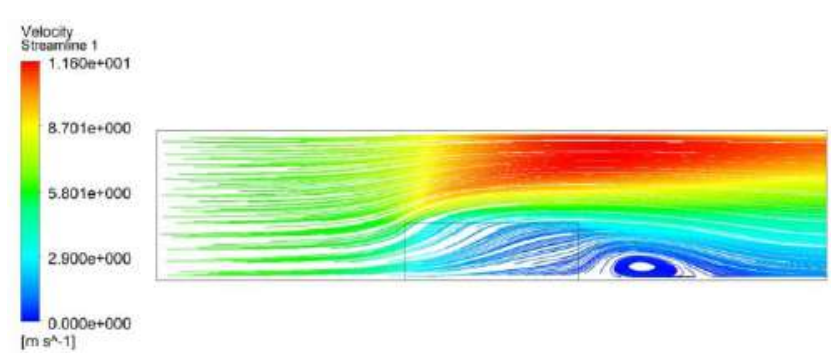

Fig. 9: Simulation of 40 PPI foam with $\mathrm{h} / \mathrm{H}=0.39$ at inlet velocity, $6.2 \mathrm{~m} / \mathrm{s}$

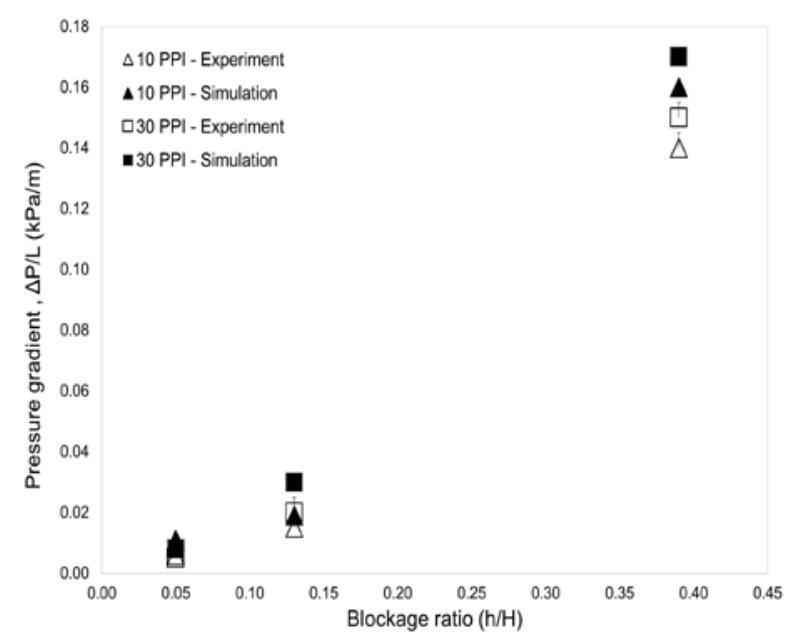

Fig. 10: Comparison of pressure gradient versus blockage ratio from present simulation and experimental data ${ }^{3}$
Fig. 10 shows a comparison of pressure drop between our simulation with experimental data $^{3)}$, where the pressure drop increases with the increases of the blockage ratio as expected. The pressure drop of a more porous structure like $30 \mathrm{PPI}$ is larger than $10 \mathrm{PPI}$, which is obviously seen in higher blockage ratio of 0.13 and 0.39 . With a lower blockage ratio, for example 0.05, similar pressure drops are found from both simulations and experiments. The simulation results show a similar pressure difference between $10 \mathrm{PPI}$ and $30 \mathrm{PPI}$ at the higher blockage ratios of 0.13 and 0.39 . However, the experimental data shows a larger difference at the highest blockage ratio. At $\mathrm{h} / \mathrm{H}=0.39$, the deviation in pressure drop between the simulation and experiment becomes more evident. The exact reason for this result is still unknown, but it is important to note that the pressure drop of a partially filled channel with the use of a real metal foam could be influenced by these three factors ${ }^{3)}$ : (1) flow restrictions due to sudden change in channel size, (2) complex structure of metal foam, and (3) large wakes at the downstream region. Most probably, the simulation results overestimated these effects. Moreover, the onset of the recirculation zone that appears starting from the interface region (Fig. 7 (h)) in a case of real metal foam may also contribute to the difference in the pressure gradients at a high blockage ratio.

\section{Conclusion}

This study used an existing porous media equation (Ergun-Forchheimer) in a CFD simulation to describe the flow behaviors in the partially filled section with open-cell metal foam. It was found that the existing classical porous medium equation can be used to describe the presence of the stagnant region with the same flow patterns as the results agree with the experimental data. The outgoing flow through the interface region can also be found in both simulation and experimental results. The results from IRT show a metal foam with higher pore density than 30 PPI would act like a solid block, where the stagnant region could be wider than a more porous foam. More research should be conducted on the interface condition and mimicking the porous structure of open-cell metal foam in the simulation should be done better as the deviation in the pressure drops between simulation and experiments is noticeable for $\mathrm{h} / \mathrm{H}>0.13$. This is an important parameter to be considered since a partially filled design was suggested to reduce the pressure drop of a metal foam heat exchanger. A higher dataset with different inlet velocities, blockage ratios and foam lengths should also be investigated to obtain a clearer picture on the flow behaviours, and consequently find an optimum pressure drop for this partially filled design. 


\section{Acknowledgements}

The preliminary numerical work of this study has been accepted and presented in MERD'20. The authors acknowledge Universiti Teknikal Malaysia Melaka, UTeM, for supporting this research work and The University of Queensland for the use of laboratory facilities. The project grant no.: FRGS/1/2020/FTKMPCARE/F00440

\section{Nomenclature}

$\begin{array}{ll}d & \text { diameter (m) } \\ \mathrm{h} & \text { foam height }(\mathrm{m}) \\ \mathrm{H} & \text { channel height }(\mathrm{m}) \\ \mathrm{h} / \mathrm{H} & \text { blockage ratio (-) } \\ \mathrm{IRT} & \text { infrared thermography } \\ \mathrm{L} & \text { channel length (m) } \\ \nabla P^{*} & \text { pressure gradient of flow direction }\left(\mathrm{Pa}^{-\mathrm{m}^{-1}}\right) \\ \mathrm{PPI} & \text { pore per inches }(-) \\ \mathrm{u} & \text { velocity }(\mathrm{m} / \mathrm{s})\end{array}$

$u^{*} \quad$ flux per unit area of the porous medium $\left(\Phi / \mathrm{m}^{-2)}\right.$

\section{Greek symbols}

$\begin{array}{ll}B & \text { inertial resistance coefficient (-) } \\ \mathcal{E} & \text { emissivity (-) } \\ \rho & \text { density }\left(\mathrm{kgm}^{-3}\right) \\ \mu & \text { dynamic viscosity }\left(\mathrm{kgm}^{-1} \mathrm{~s}^{-1}\right)\end{array}$

\section{Subscripts}

o inlet

p pore

\section{References}

1) H. Darcy, "Les Fontaines Publiques de la ville de Dijon,” Dalmont, Paris, 1856.

2) J.L. Lage, "The Fundamental Theory of Flow Through Permeable Media from Darcy to Turbulence," in: I.D.B. and I. Pop (Ed.), Transp. Phenom. Porous Media, I. D.B. and I. Pop, Eds. Elsevier Science Ltd, 1998: pp. 1-30. doi:10.1016/b978-008042843-7/50001-5.

3) F. Shikh Anuar, I. Ashtiani, M. Odabaee, and K. Hooman, "Experimental study of fluid flow behaviour and pressure drop in channels partially filled with metal foams," Exp. Therm. Fluid Sci., 99 (July) 117-128 (2018). doi:10.1016/j.expthermflusci.2018.07.032.

4) M.P. Orihuela, F.S. Anuar, I.A. Abdi, M. Odabaee, and K. Hooman, "International journal of heat and mass transfer thermohydraulics of a metal foam-filled annulus," Int. J. Heat Mass Transf., 117 95-106 (2018). doi:10.1016/j.ijheatmasstransfer.2017.10.009.

5) M.M. Takeyeldein, T.M. Lazim, I.S. Ishak, N.A.R. Nik Mohd, and E.A. Ali, "Wind lens performance investigation at low wind speed," Evergreen, 7 (4) 481-488 (2020). doi:10.5109/4150467.

6) D.A. Wulandari, M. Akmal, Y. Gunawan, and Nasruddin, "Cooling improvement of the it rack by layout rearrangement of the a2 class data center room: a simulation study," Evergreen, 7 (4) 489-499 (2020). doi:10.5109/4150468.

7) F. Shikh Anuar, I. Ashtiani Abdi, and K. Hooman, "Flow visualization study of partially filled channel with aluminium foam block," Int. J. Heat Mass Transf., $127 \quad 1197-1211 \quad$ (2018). doi:10.1016/j.ijheatmasstransfer.2018.07.047.

8) A. Arbak, N. Dukhan, Ö. Bağc1, and M. Özdemir, "Influence of pore density on thermal development in open-cell metal foam,” Exp. Therm. Fluid Sci., 86 180-188 doi:10.1016/j.expthermflusci.2017.04.012.

9) H. Wang, L.J. Guo, and K. Chen, "Theoretical and experimental advances on heat transfer and flow characteristics of metal foams," Sci. China Technol. Sci., 63 (5) 705-718 (2020). doi:10.1007/s11431019-1455-0.

10) M. Sener, A. Yataganbaba, and I. Kurtbas, "Forchheimer forced convection in a rectangular channel partially filled with aluminum foam," Exp. Therm. Fluid Sci., 75 162-172 (2016). doi:10.1016/j.expthermflusci.2016.02.003.

11) Yanuar, Ibadurrahman, A.S. Pamitran, Gunawan, and S. Mau, "Experimental investigation on the spiral pipe performance for particle-laden liquids," $\begin{array}{llll}\text { Evergreen, } & 7 & \text { (4) } 580-586 & \text { (2020). }\end{array}$ doi:10.5109/4150509.

12) F. Shikh Anuar, K. Hooman, M.R. Malayeri, and I. Ashtiani Abdi, "Experimental study of particulate fouling in partially filled channel with open-cell metal foam," Exp. Therm. Fluid Sci., 110 (September 2019) $109941 \quad$ (2020). doi:10.1016/j.expthermflusci.2019.109941.

13) A.S. Pamitran, S. Novianto, N. Mohd-Ghazali, and R.A. Koestoer, "Flow pattern of two-phase flow boiling with heat transfer and pressure drop using natural refrigerant (propane) in microchannel,"

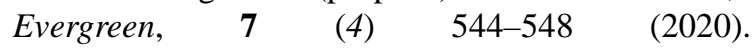
doi:10.5109/4150474.

14) B. Kotresha, and N. Gnanasekaran, "Numerical simulations of fluid flow and heat transfer through aluminum and copper metal foam heat exchanger-a comparative study," Heat Transf. Eng., 6 (2018). doi:10.1080/01457632.2018.1546969.

15) E. Sauret, K. Hooman, and S.C. Saha, "CFD simulations of flow and heat transfer through the porous interface of a metal foam heat exchanger," in: 
Am. Soc. Mech. Eng. Power Div. POWER, Maryland, USA, 2014. doi:10.1115/POWER2014-32157.

16) E. Sauret, I. Abdi, and K. Hooman, "Fouling of waste heat recovery: Numerical and experimental results," in: 19th Australas. Fluid Mech. Conf., Melbourne, Australia, 2014.

17) N. Alvandifar, M. Saffar-Avval, and E. Amani, "Partially metal foam wrapped tube bundle as a novel generation of air cooled heat exchangers," Int. J. Heat Mass Transf., $118 \quad 171-181 \quad$ (2018). doi:10.1016/j.ijheatmasstransfer.2017.10.104.

18) H. Xu, C. Zhao, and K. Vafai, "Analysis of double slip model for a partially filled porous microchannel-an exact solution," Eur. J. Mech. B/Fluids, $\quad 68 \quad 1-9 \quad$ (2018). doi:10.1016/j.euromechflu.2017.10.009.

19) A. V Kuznetsov, "Influence of the stress jump condition at the porous-medium/clear-fluid interface on a flow at a porous wall," Int. Commun. Heat Mass Transf., 24 (3) 401-410 (1997).

20) K.B. Nakshatrala, and M.S. Joshaghani, “On interface conditions for flows in coupled free-porous media," Transp. Porous Media, 130 (2) 577-609 (2019). doi:10.1007/s11242-019-01326-7.

21) A.S. Pamitran, S. Novianto, and A.S. Santoso, "Intermittent flow pattern on two phase flow boiling with horizontal microchannel," Evergreen, 7 (1) 150154 (2020). doi:10.5109/2740972.

22) A. Berg, "Numerical and experimental study of the fluid flow in porous medium in charging process of stratified thermal storage tank," KTH Industrial Engineering and Management, 2013.

23) O.M.A.M. Ibrahim, and S. Yoshida, "Experimental and numerical studies of a horizontal axis wind turbine performance over a steep 2d hill," Evergreen, 5 (3) 12-21 (2018). doi:10.5109/1957496.

24) S. Tupin, and M. Ohta, "Assessing porous media permeability in non-darcy flow: a re-evaluation based on the forchheimer equation,” Materials (Basel)., 13 (11) 2-5 (2020). doi:10.3390/ma13112535.

25) B. Kotresha, and N. Gnanasekaran, “Analysis of forced convection heat transfer through graded PPI metal foams," Springer Singapore, 2019. doi:10.1007/978-981-13-1903-7_18.

26) C. Dollinger, N. Balaresque, N. Gaudern, D. Gleichauf, M. Sorg, and A. Fischer, "IR thermographic flow visualization for the quantification of boundary layer flow disturbances due to the leading edge condition," Renew. Energy, 138 709-721

(2019). doi:10.1016/j.renene.2019.01.116.

27) J. Pérez-Barrera, G. Ramírez-Zúñiga, E.C. Grespan, S. Cuevas, and J.A. del Río, "Thermographic visualization of a flow instability in an electromagnetically driven electrolyte layer," Exp. Therm. Fluid Sci., 109 (July) 109882 (2019). doi:10.1016/j.expthermflusci.2019.109882.
28) S. Mancin, C. Zilio, L. Rossetto, and A. Cavallini, "Heat transfer performance of aluminum foams," $J$. Heat Transfer, $133 \quad$ (6) $060904 \quad$ (2011). doi:10.1115/1.4003451.

29) F. Shikh Anuar, F.A.-Z. Mohd Sa'at, and E. Mat Tokit, "Investigation of flow behaviors and temperature distribution in porous foam using infrared thermographic technique,” in: Proc. Mech. Eng. Res. Day 2020, Malacca, Malaysia, 2020: pp. 377-378.

30) N.A. Rahmat, A. Hagishima, N. Ikegaya, and J. Tanimoto, "Experimental study on effect of spires on the lateral nonuniformity of mean flow in a wind tunnel," Evergreen, 5 (1) 1-15 (2018). doi:10.5109/1929670. 